Article

\title{
Effect of Solar-Cloud-Satellite Geometry on Land Surface Shortwave Radiation Derived from Remotely Sensed Data
}

\author{
Tianxing Wang ${ }^{1, *}\left(\mathbb{D}\right.$, Jiancheng Shi ${ }^{1}$, Letu Husi ${ }^{1}$, Tianjie Zhao ${ }^{1}$, Dabin Ji ${ }^{1}$ (D), Chuan Xiong ${ }^{1}$ \\ and Bo Gao ${ }^{2}$ \\ 1 State Key Laboratory of Remote Sensing Science, Institute of Remote Sensing and Digital Earth, \\ Chinese Academy of Sciences, Beijing 100101, China; shijc@radi.ac.cn (J.S.); husiletu@radi.ac.cn (L.H.); \\ zhaotj@radi.ac.cn (T.Z.); jidb@radi.ac.cn (D.J.); xiongchuan@radi.ac.cn (C.X.) \\ 2 Beijing Laboratory of Water Resources Security, Capital Normal University, Beijing 100048, China, \\ gaobo@irsa.ac.cn \\ * Correspondence: wangtx@radi.ac.cn; Tel.: +86-10-6480-7981
}

Received: 11 May 2017; Accepted: 2 July 2017; Published: 5 July 2017

\begin{abstract}
Clouds and their associated shadows are major obstacles to most land surface remote sensing applications. Meanwhile, solar-cloud-satellite geometry (SCSG) makes the effect of clouds and shadows on derived land surface biophysical parameters more complicated. However, in most existing studies, the SCSG effect has been frequently neglected although it is pointed out by many works that SCSG effect is a noticeable problem, especially in the field of land surface radiation budget. Taking shortwave downward radiation (SWDR) as a testing variable, this study quantified the SCSG effect on the derived SWDR, and proposed an operational scheme to correct the big effect. The results demonstrate that the proposed correcting scheme is very effective and works very well. It is revealed that a significant under- or overestimation is detected in retrieved SWDR if the SCSG effect is ignored. Typically, the induced error in SWDR can reach up to $80 \%$. The scheme and findings of this study are expected to be inspirational for the land surface remote sensing community, wherein solar-cloud-satellite geometry is an unavoidable issue.
\end{abstract}

Keywords: cloud; shadow; solar-cloud-satellite geometry; shortwave downward radiation (SWDR)

\section{Introduction}

Clouds and their shadows are a major concern to the optical remote sensing of the Earth's surface. A large number of remote sensing applications, such as image classification, derivation of reflectance/Albedo, land surface temperature (LST), radiation, vegetation index as well as many other biophysical parameters are largely impacted by clouds and shadows. To weaken the influence of cloud, many cloud/shadow detection and removal approaches have been developed [1-8] for various applications. Typically, as an example, during the image classification, the cloud removal process is widely used by assuming the surface cover types are unchanged over a short time scale (e.g., a few days). While the energy-related parameters, such as land surface shortwave (SWR) or longwave radiation (LWR), can never be deemed as static even in a half hour, therefore, the traditional cloud removal techniques cannot be applicable in these cases. A possible way to derive land surface cloudy-sky radiation is to quantify the scattering/absorption (shortwave) or thermal emittance (longwave) induced by clouds on radiation. Because of this, existing radiation derivation algorithms can be grouped into two categories, i.e., some are designed for only clear-sky conditions, and others are designed for cloudy conditions. To date, although the estimation of cloudy-sky surface radiation has made great progress, the effect of solar-cloud-sensor geometry 
on satellite-derived surface radiation has not yet been fully considered in many works, leading to the incorrect estimation of radiation for cloudy or shaded areas. Actually, the important issue of solar-cloud-sensor geometry and similar parallax effect on remote sensing has been pointed out by many researches. For instance, Schutgens and Roebeling [9] compared the satellite-derived liquid water path with ground measurements under cloudy skies and concluded that the induced errors resulting from the shadowing-illumination geometry effect are significantly large. Li et al. (2013) [10] characterized the solar-cloud-sensor geometry effect while conducting the removal of cloud shadows in MSG/SEVIRI imagery. Iwabuchi and Hayasaka [11] also addressed the cloud geometry effect on optical thickness estimation. With regard to the land surface radiation, however, a vast majority of works have mainly focused on the influence of solar absorption or scattering due to the plane-parallel assumption (vertically homogenous) of cloud structure [12-17]. The solar-cloud-sensor geometry influence as well as its correction has received relatively little attention, and only a few works have directly addressed and corrected the solar-cloud-sensor geometry effect on satellite-derived land surface radiation $[18,19]$. This is our main motivation in this study. More importantly, the solar-cloud-sensor geometry or parallax effect is still neglected in most works, especially in the field of surface radiation budget, although a lot of studies have emphasized the problem $[9,10,18,19]$. Thus, the purpose of this paper is to characterize the influence of solar-cloud-sensor geometry on derived land surface radiation from space, and then to provide an operational scheme to correct the big effect.

Specifically, for a remote sensing image, according to most existing radiation retrieval approaches [20-30], the criteria used to determine whether a pixel is suitable for a cloudy-sky or clear-sky algorithm mainly depend on the result of cloud detection. While the fact is that both solar and satellite-sensor have certain zenith and azimuth angles, the cloudy pixels shown on a remotely sensed image are only projections of the corresponding cloud at the observing direction, but not the cloud orthographic projections on the ground. The projected and the actual location of the cloud will certainly have a large deviation if the observing and the solar zenith angles are relatively large. As shown in Figure 1, region B is the orthographic projection position of the cloud on the ground, region $C$ is cloud projection on the image (cloud pixels shown in the image), and region $A$ is the cloud shadow on the image. According to the processing manner of currently existing algorithms, region $C$ is considered to be affected by cloud, so the cloudy-sky algorithm is employed. At the same time, A is accordingly deemed as under clear-sky conditions and the clear-sky algorithm is thus adopted. However, in fact, it is region A that is really contaminated by the clouds, not region C, so in existing algorithms, the estimation of radiation in both regions $\mathrm{A}$ and $\mathrm{C}$ are fairly unbelievable. Strictly speaking, the existing approaches to derive surface cloudy-sky radiation are valid only for the nadir case for both solar and satellite-sensor (both zenith angles equal to 0 for certain cloudy pixels). In other words, the most-used radiation retrieval methods only utilize a typically vertical one-dimension approach, but not a three-dimension consideration, thus the SCSG effect can never be addressed. In particular, the large impact of the solar-cloud-sensor geometry on land surface radiation will be enlarged in polar-orbit satellite data acquired at higher latitudes or in images collected by stationary satellites around sunrise or sunset wherein the solar zenith angle is relatively large. Therefore, to obtain the true spatio-temporal distribution of surface radiation, the significant influence of solar-cloud-sensor geometry should be taken into account and effectively corrected during the retrieval based on remotely sensed data. Note that, except for the surface radiation, all other surface parameters, such as LST and albedo, are also seriously disturbed by clouds. Here, although land surface radiation is selected as a case study, the correction scheme is general and can easily be adopted for other remotely sensed surface variables.

The remainder of this paper is structured as follows. Section 2 describes the datasets employed in this study. Section 3 presents an approach to calculate the orthographic positions of clouds and their shadows, which is followed by a description of the method for deriving land surface shortwave radiation based on MODIS data. Also, the characterization and correction scheme regarding the SCSG effect are suggested at the end of this section. Section 4 demonstrates the performance of the proposed 
scheme. The applicability and issues related to the proposed method are discussed in Section 5, and finally, the conclusions are provided in Section 6.

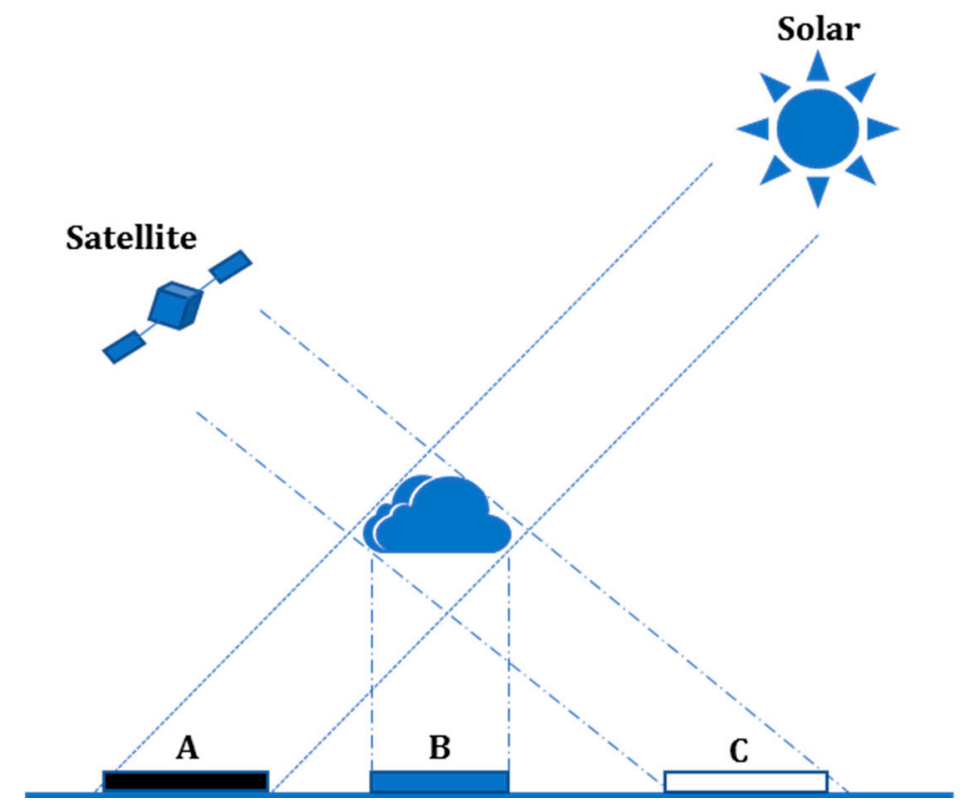

Figure 1. Schematic diagram of solar-cloud-sensor geometry. (A: cloud shadow, B: cloud orthographic position on the ground, $\mathbf{C}$ : cloud projection on the image (cloud pixel shown in the image)).

\section{Satellite Datasets}

MODIS, onboard the Terra and Aqua satellites, is one of the most advanced instruments currently available for global land and atmosphere monitoring which can be evidenced by its relatively high spectral and spatial resolutions [31-33]. Furthermore, various MODIS cloud and land products are readily available to the scientific community providing an unprecedented opportunity for accurately mapping land surface radiation from space. The main MODIS products used in this study include cloud parameters (MOD06), cloud mask (MOD35), radiance (MOD02), geolocation (MOD03) and albedo (MOD43) products.

\section{Methods}

\subsection{Determination of Orthographic Positions of Clouds and Their Shadows}

Cloud orthographic position is very critical for characterizing solar-cloud-sensor geometry and together with cloud top height, it is an indispensable variable in determining the scope of cloud shadow. Theoretically, it is straightforward to determine the cloud actual position if providing cloud height, zenith and azimuth angles of both solar and satellite as well as the cloud projection on the remotely sensed image. In this study, the needed angles and cloud height are derived from MOD03 and MOD06 products. Orthographic positions of the cloud and associated shadow are determined using the following formula. An alternative effective shadow detection approach can be referred to [8].

$$
\begin{aligned}
& X_{c l d}=x_{\text {map }}+H \tan \theta_{v} \sin \varphi_{v} \\
& Y_{c l d}=y_{\text {map }}+H \tan \theta_{v} \cos \varphi_{v} \\
& X_{\text {shw }}=X_{\text {cld }}-H \tan \theta_{s} \sin \varphi_{s} \\
& Y_{\text {shw }}=Y_{c l d}-H \tan \theta_{s} \cos \varphi_{s}
\end{aligned}
$$


where $\left(X_{\text {shw }}, Y_{\text {shw }}\right)$ is the orthographic position of cloud shadow on the surface; $\left(X_{c l d}, Y_{c l d}\right)$ is cloud vertical projection on the surface; $\left(x_{\text {map }}, y_{\text {map }}\right)$ is cloud projection in the remotely sensed image which is probably a pseudo position; $H$ is cloud top height above the surface, in this study it is the difference between the cloud top height from MOD06 minus the surface elevation from MOD03; $\theta_{v}$ and $\varphi_{v}$ are the observing zenith and azimuth angles, respectively; and $\theta_{s}$ and $\varphi_{s}$ are the solar zenith and azimuth angles, respectively. Note that, in Equations (1) and (2), the azimuth angle is in the range of $\left[-180^{\circ}, 180^{\circ}\right]$, the true north is at 0-degree azimuth, east has an azimuth of $90^{\circ}$, and west has an azimuth of $-90^{\circ}$.

\subsection{Estimation of Land Surface Shortwave Downward Radiation (SWDR)}

In this paper, we take land surface shortwave downwelling radiation as a test parameter considering its importance in driving various application models such as hydrology, climate, meteorology, ecosystem and evapotranspiration, etc. Because too many studies have been conducted to derive shortwave downwelling radiation in the literature [21-23,34-37], in this paper we do not attempt to improve or develop new approaches for deriving surface radiation instead, we mainly focus on the quantification of the effect of solar-cloud-sensor geometry on the derived surface SW radiation, regardless of the specific algorithms that are employed to derive the corresponding radiation. As a result, the concern of more accurate radiation retrieval methods is beyond the scope of this paper. In this paper, the algorithm suggested by Frouin and Chertock [38] is adopted considering its easy operation and higher accuracy [38-40]. For pixels under clear-sky conditions, Formula (3) is utilized otherwise, Formula (4) is performed (for cloudy skies). A pixel in an image is designated as clear or cloudy depend on the MODIS cloud mask product. The needed atmospheric water vapor, aerosol, and land surface albedo are extracted from the corresponding MODIS products.

$$
\begin{gathered}
S W D R_{\text {clear }}=E_{0} \cos \left(\theta_{s}\right) T\left(1-S_{a} A_{s}\right)^{-1} \\
S W D R_{\text {cloud }}=\frac{E_{0} \cos \left(\theta_{s}\right) T(1-A)}{\left(1-S_{a} A\right)\left(1-A_{s}\right)}
\end{gathered}
$$

where, $S W D R_{\text {clear }}$ and $S W D R_{\text {cloud }}$ are the shortwave flux reaching the surface under clear-sky and cloudy-sky conditions, respectively; $E_{0}$ is solar constant; $\theta_{s}$ is the solar zenith angle; $T$ is the atmospheric total transmittance (diffuse and direct) accounting for aerosol and gaseous scattering and absorption; $S_{a}$ is the atmospheric spherical albedo which is estimated using MODTRAN5 radiative transfer code based on typical atmospheric conditions; and $A_{S}$ and $A$ are the broadband albedo of land surface and cloud layer, respectively. The MODIS narrowband albedo (bands 1-7) was converted to that of broadband using the method suggested by Liang [41].

\subsection{Solar-Cloud-Sensor Geometry Effect Correction}

The solar-cloud-sensor geometry effect on SWDR can be grouped into two categories (Figure 2). (1) No cloud shadow is observed in the image; and (2) Partial or entire cloud shadow is shown in the image. For category (1), as mentioned in Section 1, it meets the assumption requirement of current approaches, i.e., as long as the pixel is covered by cloud on the image, then the cloudy-sky algorithm is accordingly adopted, so it is unnecessary to further correct under this situation. For category (2), three cases should be considered. D: Shadow is shown on the image; E: shadow is covered by cloud, and F: bright surface is contaminated by cloud. Because most existing SWDR retrieval algorithms mainly depend on atmospheric attenuation by aerosol, water vapor and molecular gases etc., the SWDR of a cloud shadow region (see case $\mathbf{D}$ ) in the remote sensing image is obviously overestimated. By contrast, in case $\mathbf{F}$, the surface is actually not obstructed by cloud, but it is treated as a cloudy area in existing approaches, so the corresponding SWDR is substantially underestimated. Although both case $\mathbf{D}$ and case $\mathbf{E}$ are for cloud shadow, they are differently treated in most currently existing methods, i.e., case $\mathbf{D}$ is dealt with using a clear-sky algorithm, while case $\mathbf{E}$ is considered using a cloudy-sky manner, 
this is the main difference between these two cases. Please note that, although case $\mathbf{E}$ is deemed as a cloudy pixel in the existing approaches, the derived SWDR is, however, still incorrect. The reason for this is that the cloud portion that really affects the area of $\mathbf{E}$ is not necessarily the vertically overlapped one. For instance, for the left graph of category (2) in Figure 2, the cloud portion that affects the SWDR of case $\mathbf{E}$ is $\mathbf{P 1}$ according to the processing manner of existing algorithms, but the cloud portion that really obstructs the solar energy reaching the surface of $\mathbf{E}$ is $\mathbf{P} 2$ because of the non-zero solar zenith angle. Moreover, in most cases, the radiation scattering and transmittance for $\mathbf{P 1}$ and $\mathbf{P} 2$ are probably different due to the inhomogeneity of the cloud structure. Of course, the derived SWDR for case E without SCSG effect correction may also be accurate under the extreme situation that the whole cloud layer is spatially homogeneous in terms of microphysical property and light attenuation, which, however, rarely occurs in practice. Thus, the SCSG effect correction for case $\mathbf{E}$ of category (2) is also important and necessary.
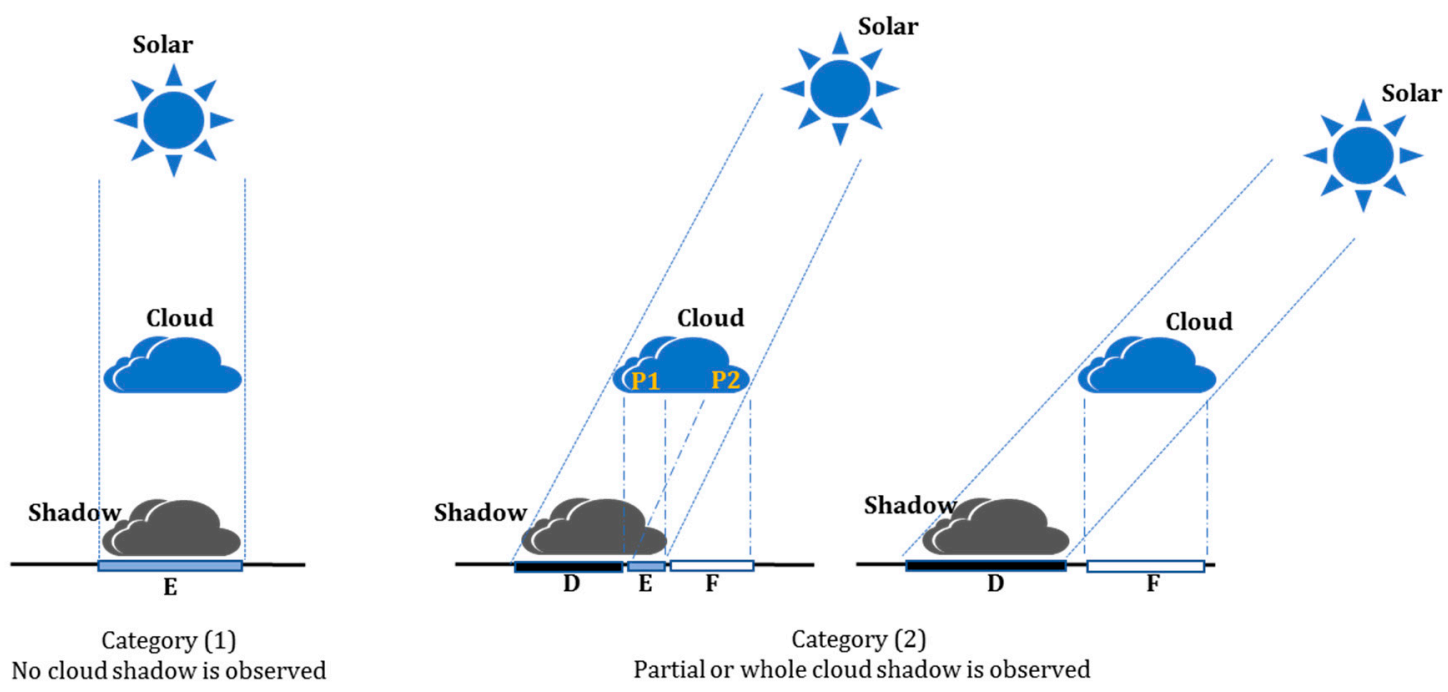

Figure 2. Three cases for correcting solar-cloud-sensor geometry effect on derived SWDR from space. (D: Shadow shown on the image; E: shadow covered by cloud, and F: bright surface covered by cloud).

According to the above analysis, all three cases of D, E and F should be properly corrected. For cases D and E, the Equations (1) and (2) were first used to determine the cloud and its shadow scope pixel by pixel, and the relationship of each cloudy pixel and its shadow projection is stored. For each cloudy pixel, the calculated SWDR in Section 3.2 was designated to its shadow pixel, and this process was performed iteratively pixel by pixel for all cloudy pixels in the image. For case $\mathbf{F}$, the pixels can be illuminated by the solar, so the SWDR for these pixels should be very similar to that of nearby clear-sky pixels within a short distance. In this paper, the SWDR of those pixels (under case F) are approximated using the values of the nearest clear-sky pixels within a $10 \times 10$ window. Finally, a solar-cloud-sensor geometry corrected SWDR was generated.

\section{Results}

In this section, the performance of the proposed correction scheme is tested based on the Terra-MODIS $1 \mathrm{~km}$ data. In Figure 3, a subset of the MODIS Terra image acquired at 05:55 (UTC) on 2 February 2010 covering part of the Tibetan plateau region is shown [42].

From Figure 3, by comparing with MODIS L1B RGB image, it can be seen that all three affected cases D, E and F can be properly characterized using the proposed scheme. To better illustrate the big impact of solar-cloud-sensor geometry on SWDR, the SCSG effect-corrected SWDR is subtracted by the SWDR wherein solar-cloud-sensor geometry is not considered (Figure 4). From the difference map, we can see that the shadow area (green region in Figure 3) in the image has negative values, 
and the cloud region (blue region in Figure 3) possesses positive values, demonstrating that if the solar-cloud-sensor geometry effect is neglected, the derived SWDR will be underestimated at the cloudy area and overestimated at the shadow region. The specific magnitude of the difference varies with the cloud physical and optical features. In our case, the difference can reach up to $500 \mathrm{~W} / \mathrm{m}^{2}$, which count about $80 \%$ of clear-sky SWDR.

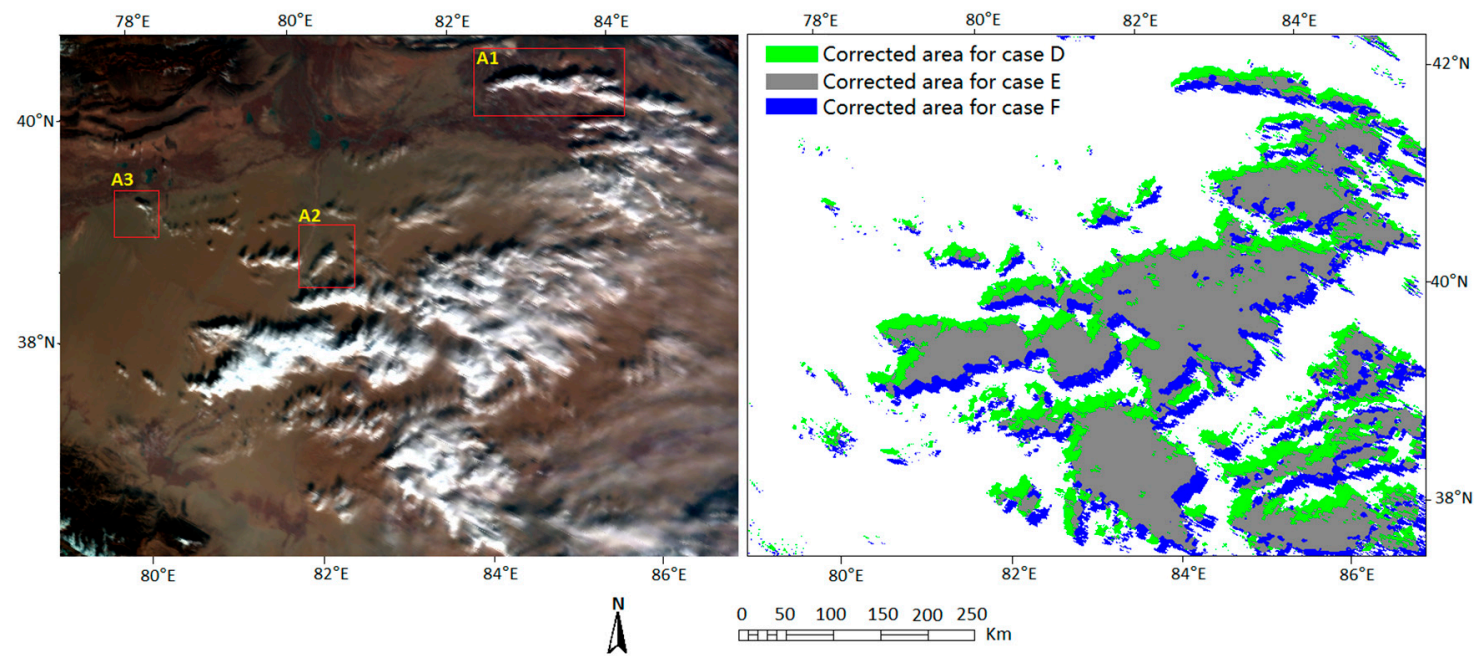

Figure 3. Corrected SWDR regions for the three cases illustrated in Figure 2. (left: MODIS bands 2-4 for R,G,B; right: three cases affected by solar-cloud-sensor geometry, i.e., green: Shadow shown on the image; gray: shadow covered by cloud, and blue: bright surface covered by cloud. A1, A2 and A3 are three subset regions selected for detailed comparison in subsequent analysis).

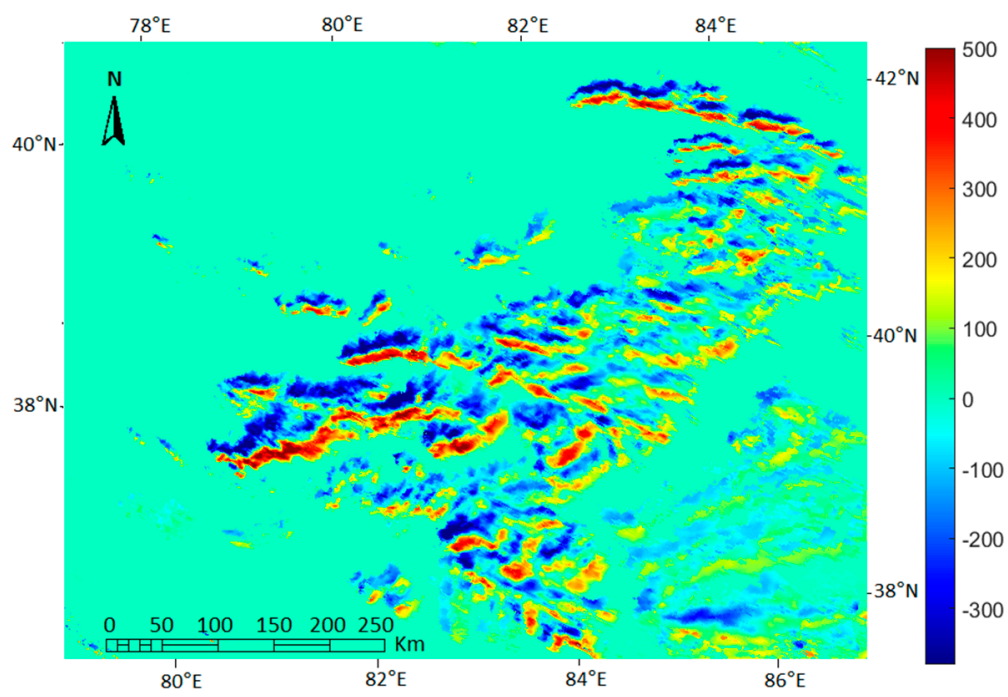

Figure 4. Difference map of SWDR $\left(\mathrm{W} / \mathrm{m}^{2}\right)$. (Corrected SWDR minus original one wherein solar-cloud-sensor geometry is not considered).

To visually evaluate the performance of the suggested correction scheme, three subset regions (see red rectangles in Figure 3) were randomly chosen to test. Figure 5 lists the comparison results. In regions of A1-A3, it is easy to see the situations of under- or overestimation of SWDR as indicated in Figure 4. Typically, in region A1, four cross signs are marked indicating the collocated positions. It shows that the shadow areas wherein the corresponding SWDR should be lower are seriously overestimated if ignoring the geometry effect (column 3rd), while this is properly corrected using the 
proposed scheme (column 4th). At the same time, the SWDRs of pixels which are covered by cloud in the image but are unobstructed in practice (blue areas) are also recovered in the corrected SWDR map. This can be evidenced by the marked points in region A2. The test of A3 also demonstrates the satisfactory performance and effectiveness of the correction scheme.
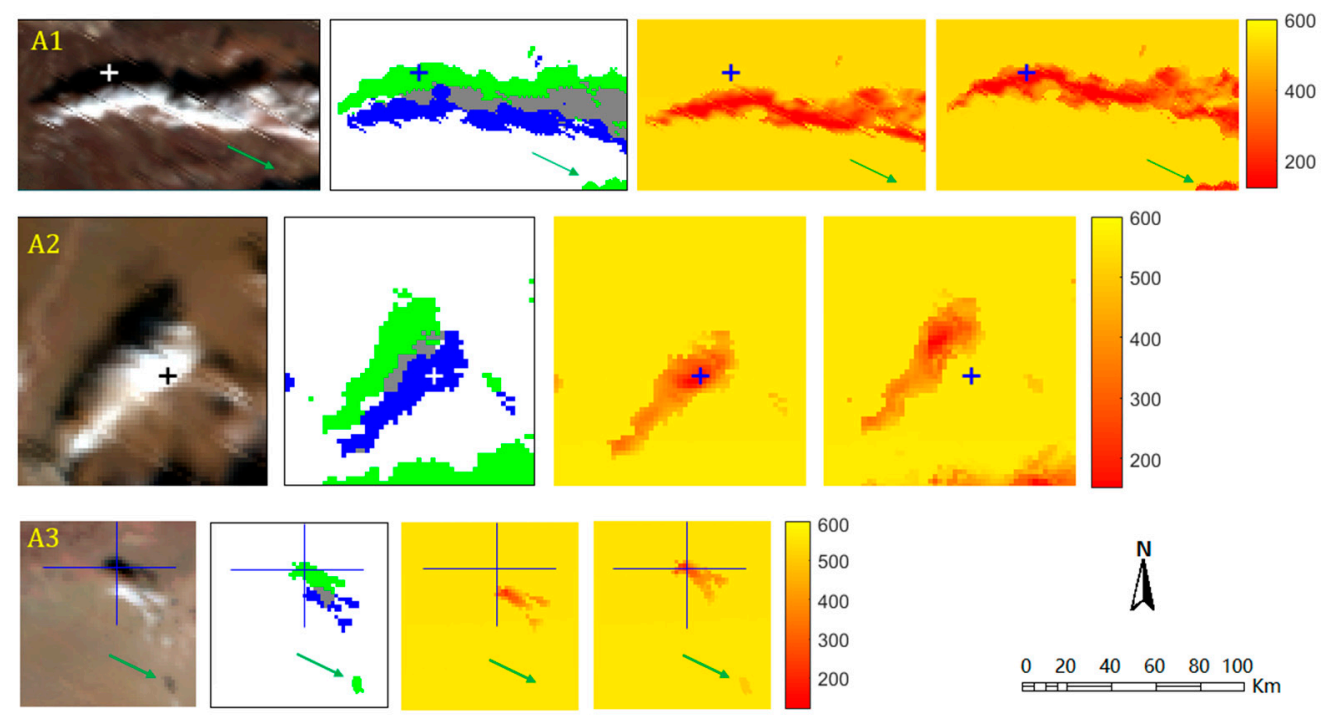

Figure 5. Correction performance of the proposed scheme for three enlarged subset images shown in Figure 3 (please see regions of A1, A2 and A3). (Four columns from left to right: MODIS-L1B RGB image; corrected area for three situations; original SWDR without solar-cloud-sensor geometry correction and the corrected SWDR. The legend is the same as that in Figure 3).

\section{Discussion}

In this paper, the SWDR is selected as a testing variable. Since the main objective of this study is to quantify the solar-cloud-sensor geometry effect on derived surface radiation from space and to provide an effective approach to correct the corresponding effect, the specific algorithm for retrieving SWDR as well as its absolute accuracy are beyond the scope of this paper. It is easy to see that the reliability of the proposed correction mainly depends on the accuracy of cloud detection, cloud height, solar or viewing angles, and the derived radiation itself. Although any uncertainties in the abovementioned variables may theoretically affect the final result of the corrected radiation, it is not a problem deserving special attention, considering the continuous progress of remote sensing technology. At least, in the present case study, this is not a problem. The uncertainties of associated variables involved in the newly proposed scheme cannot deny its feasibility and the main findings of this paper. More importantly, it is the correction scheme and the findings in this paper, but not the accuracy itself that is truly important to the research on remote sensing of the Earth's surface, wherein solar-cloud-sensor geometry is an unavoidable problem.

\section{Conclusions}

In this study, the geometry effect of solar-cloud-sensor on surface radiation is characterized. An effective correction scheme for three cases was proposed by considering cloud top height and solar and viewing angles. A case study based on MODIS-Terra data was conducted. It is found that a noticeable under- or overestimation is detected in estimated SWDR if the solar-cloud-sensor geometry effect is ignored during the retrieval. The discrepancy in SWDR can reach up to $80 \%$, implying that the geometry effect on surface radiation should be given adequate attention in the future. The overestimation mainly occurs in cloud shadow areas shown in the remotely sensed image, while underestimation is frequently distributed in regions where the surfaces are illuminated by the 
sun but covered by clouds in the image. The tests revealed that the proposed correction scheme is very effective. The motivation and findings in this study can benefit the Earth-observing community in dealing with the effect of solar-cloud-observing geometry on derived biophysical variables.

Acknowledgments: The work of this paper are partially supported by the National Key Basic Research Program of China (973 Program) (2015CB953701), NSFC project (41331171, 41571364, 41501380) and the International Partnership Program of Chinese Academy of Sciences, Grant No. 131C11KYSB20160061.

Author Contributions: T.W., J.S. and L.H. proposed the method, designed and performed the experiments; T.Z., D.J., C.X., and B.G analyzed the data and provided constructional suggestions; T.W. wrote the paper.

Conflicts of Interest: The authors declare no conflict of interest.

\section{References}

1. Lv, H.; Wang, Y.; Shen, Y. An empirical and radiative transfer model based algorithm to remove thin clouds in visible bands. Remote Sens. Environ. 2016, 179, 183-195. [CrossRef]

2. Menaka, E.; Kumar, S.; Bharathi, M. Cloud removal using efficient cloud detection and removal algorithm for high-resolution satellite imagery. J. Comput. Appl. Technol. 2015, 51, 54-61. [CrossRef]

3. Eckardt, R.; Berger, C.; Thiel, C.; Schmullius, C. Removal of Optically Thick Clouds from Multi-Spectral Satellite Images Using Multi-Frequency SAR Data. Remote Sens. 2013, 5, 2973-3006. [CrossRef]

4. Paudel, K.P.; Andersen, P. Monitoring snow cover variability in an agropastoral area in the Trans Himalayan region of Nepal using MODIS data with improved cloud removal methodology. Remote Sens. Environ. 2011, 115, 1234-1246. [CrossRef]

5. Li, J.; Liu, C.; Huang, H.; Schmit, T.J.; Wu, X.; Menzel, W.; Gurka, J.J. Optimal cloud-clearing for AIRS radiances using MODIS. IEEE Trans. Geosci. Remote Sens. 2005, 43, 1266-1278.

6. Gafurov, A.; Bardossy, A. Cloud removal methodology from MODIS snow cover product. Hydrol. Earth Syst. Sci. 2009, 13, 1361-1373. [CrossRef]

7. Tseng, D.; Tseng, H.; Chien, C. Automatic cloud removal from multi-temporal SPOT images. Appl. Math. Comput. 2008, 205, 584-600. [CrossRef]

8. Díaz, F.; Montero, H.; Santana, D.; Montero, G.; Rodríguez, E.; Aguiar, L.M.; Oliver, A. Improving shadows detection for solar radiation numerical models. Appl. Math. Comput. 2017, in press.

9. Schutgens, N.A.J.; Roebeling, R.A. Validating the validation: The influence of liquid water distribution in clouds on the intercomparison of satellite and surface observations. J. Atmos. Ocean. Technol. 2009, 26, 1457-1474. [CrossRef]

10. Li, S.; Sun, D.; Yu, Y. Automatic cloud-shadow removal from flood/standing water maps using MSG/SEVIRI imagery. Int. J. Remote Sens. 2013, 34, 5487-5502. [CrossRef]

11. Iwabuchi, H.; Hayasaka, T. Effects of cloud horizontal inhomogeneity on the optical thickness retrieved from moderate-resolution satellite data. J. Atmos. Sci. 2002, 59, 2227-2242. [CrossRef]

12. O'Hirok, W.; Gautier, C. A three-dimensional radiative transfer model to investigate the solar radiation within a cloudy atmosphere. Part I: Spatial effects. J. Atmos. Sci. 1998, 55, 2162-2179. [CrossRef]

13. Fu, Q.; Cribb, M.C.; Barker, H.W.; Krueger, H.W.; Grossman, A. Cloud geometry effects on atmospheric solar absorption. J. Atmos. Sci. 2000, 57, 1156-1168. [CrossRef]

14. Várnai, T. Influence of three-dimensional radiative effects on the spatial distribution of shortwave cloud reflection. J. Atmos. Sci. 2000, 57, 216-229. [CrossRef]

15. Barker, H.W.; Stephens, G.L.; Partain, P.T.; Bergman, J.W.; Bonnel, B.; Campana, K.; Edwards, J. Assessing 1D atmospheric solar radiative transfer models: Interpretation and handling of unresolved clouds. J. Clim. 2003, 16, 2676-2699. [CrossRef]

16. Di Giuseppe, F.; Tompkins, A.M. Effect of spatial organization on solar radiative transfer in three-dimensional idealized stratocumulus cloud fields. J. Atmos. Sci. 2003, 60, 1774-1794. [CrossRef]

17. Hogan, R.J.; Shonk, J.K. Incorporating the effects of 3D radiative transfer in the presence of clouds into two-stream multilayer radiation schemes. J. Atmos. Sci. 2013, 70, 708-724. [CrossRef]

18. Posselt, R.; Mueller, R.W.; Stöckli, R.; Trentmann, J. Remote sensing of solar surface radiation for climate monitoring-The CM-SAF retrieval in international comparison. Remote Sens. Environ. 2012, 118, 186-198. [CrossRef] 
19. The HelioMont Surface Solar Radiation Processing. Available online: https://www.gr.ch/DE/institutionen/ verwaltung/dvs/are/Documents/heliomont_scientific_report.pdf (accessed on 11 May 2017).

20. Yan, G.; Wang, T.; Jiao, Z.; Mu, X.; Zhao, J.; Chen, L. Topographic radiation modeling and spatial scaling of clear-sky land surface longwave radiation over rugged terrain. Remote Sens. Environ. 2016, 172, 15-27. [CrossRef]

21. Wang, T.; Yan, G.; Chen, L. Consistent retrieval methods to estimate land surface shortwave and longwave radiative flux components under clear-sky conditions. Remote Sens. Environ. 2012, 124, 61-71. [CrossRef]

22. Bisht, G.; Bras, R.L. Estimation of net radiation from the MODIS data under all sky conditions: Southern Great Plains case study. Remote Sens. Environ. 2010, 114, 1522-1534. [CrossRef]

23. Kim, H.Y.; Liang, S. Development of a hybrid method for estimating land surface shortwave net radiation from MODIS data. Remote Sens. Environ. 2010, 114, 2393-2402. [CrossRef]

24. Gupta, S.K.; Kratz, D.P.; Stackhouse, P.W., Jr.; Wilber, A.C.; Zhang, T.; Sothcott, V.E. Improvement of surface longwave flux algorithms used in CERES processing. J. Appl. Meteorol. Climatol. 2010, 49, 1579-1589. [CrossRef]

25. Wang, W.; Liang, S. Estimation of high-spatial resolution clear-sky longwave downward and net radiation over land surfaces from MODIS data. Remote Sens. Environ. 2009, 113, 745-754. [CrossRef]

26. Zhou, Y.; Kratz, D.P.; Wilber, A.C.; Gupta, S.K.; Cess, R.D. An improved algorithm for retrieving surface downwelling longwave radiation from satellite measurements. J. Geophys. Res. 2007, 112, 1-13. [CrossRef]

27. Tang, B.; Li, Z.; Zhang, R. A direct method for estimating net surface shortwave radiation from MODIS data. Remote Sens. Environ. 2006, 103, 115-126.

28. Bisht, G.; Venturini, V.; Islam, S.; Jiang, L. Estimation of the net radiation using MODIS data for clear sky days. Remote Sens. Environ. 2005, 97, 52-67. [CrossRef]

29. Zhou, Y.P.; Cess, R.D. Algorithm development strategies for retrieving the downward longwave flux at the Earth's surface. J. Geophys. Res. 2001, 106, 12477-12488. [CrossRef]

30. Gupta, S.K. A parameterization for longwave surface radiation from Sun-synchronous satellite data. J. Clim. 1998, 2, 305-320. [CrossRef]

31. Masuoka, E.; Fleig, A.J.; Wolfe, R.E.; Patt, F.S. Key characteristics of MODIS data products. IEEE Trans. Geosci. Remote Sens. 1998, 36, 1313-1323. [CrossRef]

32. Justice, C.O.; Vermote, E.; Townshend, J.R.; Defries, R.S.; Roy, D.P.; Hall, D.K.; Salomonson, V.V.; Privette, J.L.; Riggs, G.; Strahler, A.; et al. The Moderate Resolution Imaging Spectroradiometer (MODIS): Land remote sensing for global change research. IEEE Trans. Geosci. Remote Sens. 1998, 36, 1228-1249. [CrossRef]

33. Justice, C.O.; Townshend, J.R.G.; Vermote, E.F.; Masuoka, E.; Wolfe, R.E.; Saleous, N.; Roy, D.P.; Morisette, J.T. An overview of MODIS land data processing and product status. Remote Sens. Environ. 2002, 83, 3-15. [CrossRef]

34. Zhang, X.; Liang, S.; Zhou, G.; Wu, H.; Zhao, X. Generating Global LAnd Surface Satellite incident shortwave radiation and photosynthetically active radiation products from multiple satellite data. Remote Sens. Environ. 2014, 152, 318-332. [CrossRef]

35. Zheng, T.; Liang, S.; Wang, K. Estimation of Incident Photosynthetically Active Radiation from GOES Visible Imagery. J. Appl. Meteorol. Climatol. 2008, 47, 853-868. [CrossRef]

36. Liang, S.; Zheng, T.; Liu, R.; Fang, H.; Tsay, S.C.; Running, S. Mapping incident Photosynthetically Active Radiation (PAR) from MODIS Data. J. Geophys. Res. 2006, 111. [CrossRef]

37. Li, Z.; Leighton, H.G.; Masuda, K.; Takashima, T. Estimation of SW flux absorbed at the surface from TOA reflected flux. J. Clim. 1993, 6, 317-330. [CrossRef]

38. Frouin, R.; Chertock, B. A technique for global monitoring of net solar irradiance at the ocean surface. Part I: Model. J. Appl. Meteorol. 2010, 31, 943. [CrossRef]

39. Dedieu, G.; Deschamps, P.Y.; Kerr, Y.H. Satellite estimation of solar irradiance at the surface of the earth and of surface albedo using a physical model applied to metcosat data. J. Appl. Meteorol. 1986, 26, $79-87$. [CrossRef]

40. Frouin, R.; Murakami, H. Estimating photosynthetically available radiation at the ocean surface from adeos-ii global imager data. J. Oceanogr. 2007, 63, 493-503. [CrossRef] 
41. Liang, S. Narrowband to broadband conversions of land surface albedo I: Algorithms. Remote Sens. Environ. 2001, 76, 213-238. [CrossRef]

42. Available online: ftp://ladsweb.modaps.eosdis.nasa.gov/allData/6/MOD021KM/2010/033/ (accessed on 11 May 2017). 